\title{
Weight loss pressure on a 5 year old wrestler
}

\section{R A Sansone, R Sawyer}

Br J Sports Med 2005;39:e2 (http://www.bisportmed.com/cgi/content/full/39/1/e2). doi: 10.1136/bjsm.2004.013136

The case is reported of a 5 year old boy who was pressured to lose weight in order to wrestle at a lower weight class. Although a minority of athletes engage in unhealthy weight management practices, this is an unusual case because of the age of the athlete and the influential role of a parent.

$\mathrm{T}$ he vulnerability of male athletes, particularly wrestlers, to unhealthy weight management practices is well known. In a survey of 47 college wrestling teams, respondents indicated that coaches and fellow team members were the primary influences on their approaches to weight management, which included gradual dieting (79.4\%), increased exercise $(75.2 \%)$, fasting $(54.8 \%)$, and the use of saunas $(27.6 \%)$ or rubber/plastic suits $(26.7 \%) .{ }^{1}$ In addition to the medical risks posed by some of these weight loss methods, such as hypokalaemia and dehydration, athletes may also be at risk of developing eating disorders, ${ }^{2}$ especially those in sports that emphasise leanness or a low body weight. ${ }^{3}$ The following case illustrates an unusual intersection of sports, parental influence, and unhealthy weight management practices. One disturbing aspect of this case is the age of the athlete.

\section{CASE REPORT}

Bennie is a 5 year old boy and a member of a local wrestling team. Father, aged 40, was a modestly successful wrestler, and brother, aged 15, was a successful wrestler and had garnered an award at the national level. Father was actively involved in the wrestling activities of both boys and attended every competition.

On the day of weigh ins for the end of season final competition, the coach of the team overheard Bennie comment to his team mates, "Why are all of you eating before weigh ins?" This comment caught the coach's attention, who suspected that the father was pressuring Bennie, who weighed $22.7 \mathrm{~kg}$, to wrestle in a lower weight class which would require a weight loss of $2.27 \mathrm{~kg}$, or $10 \%$ of Bennie's current body weight. Bennie continued to besiege his team mates with inquiries. "I'll bet that I was the only one in the sauna last night. I haven't had anything to eat today, or yesterday."

The coach promptly contacted Bennie's father to confirm these disclosures. Father sheepishly admitted that he may have gone "overboard" in his athletic management of Bennie, and that it was inappropriate. But, father emphasised that he only wanted Bennie to be successful like himself and his older brother. The coach emphasised that this behaviour was "a clear violation of the rules," referring to the modified rules used by the team, which are based on the National Federation of State High School Associations Wrestling Rules Book. ${ }^{4}$ Section 4 (weight classifications), article 3 states that, "at anytime, the use of sweat boxes; hot showers; whirlpools; rubber, vinyl, and plastic-type suites; or similar artificial heating devices...is prohibited and shall disqualify an individual from competition" ( $p$ 15). On further exploration by the coach, the rationale for weight loss became clear. Bennie had only lost one match during the season; by wrestling in a lower weight class for the final tournament, he would be able to avoid a match with the one competitor to whom he had lost during the season. As this was the last match of the season, there was no further follow up with this case, although the coaching staff plans to monitor the situation next season.

\section{DISCUSSION}

Parents can clearly have strong influences on children through their expectations. In this particular case, father was placing inappropriate pressure on a child as well as instigating unsafe weight management practices. Fortunately, intervention by the coach was successful. However, the level of parental coercion among young athletes, and its role as a contributory variable in the development of unhealthy weight management practices among lean-sport participants is unknown.

Can male athletes be protected from unsafe weight management practices? Perhaps to some degree, they can. For example, coaches and trainers can encourage young men to share their concerns about body image and weight," remain alert to the use of potentially dangerous weight management practices and/or the emergence of eating disorder symptoms, ${ }^{3}$ and undergo more training in the area of nutrition. ${ }^{6}$ In addition, the National Collegiate Athletic Association has adopted new weight control rules ${ }^{1}$ which emphasise: competition, not weight control; reduction of incentives for rapid weight loss; and the elimination of tools used to accomplish rapid dehydration. ${ }^{7}$ One fundamental aspect of the approach appears to be to create a new "culture" around these issues.

Although awareness of unsafe weight management practices and eating pathology among male athletes is increasing, the potential influences of coaches and team mates have been little studied. These influences may be critically importantin either a beneficial or detrimental manner.

\section{Authors' affiliations}

R A Sansone, Wright State University School of Medicine, Dayton, $\mathrm{OH}$, USA

R Sawyer, Kettering Medical Center, Kettering, OH, USA

Correspondence to: Dr Sansone, Wright State University School of Medicine, Sycamore Primary Care Center, 2115 Leiter Road, Miamisburg, OH 45342, USA; Randy.sansone@kmcnetwork.org

Accepted 8 June 2004

Conflict of interests: none declared

\section{REFERENCES}

1 Oppliger RA, Steen SA, Scott JR. Weight loss practices of college wrestlers. Int J Sport Nutr Exerc Metab 2003;13:29-46.

2 Wilmore JH. Eating disorders in the young athlete. In: Bar-Or O, ed. The child and adolescent athlete. Champaign, IL: Blackwell Science, 1996:287-303. 
3 Garner DM, Rosen LW, Barry D. Eating disorders among athletes: research and recommendations. Child Adolesc Psychiatr Clin N Am 1998;7:839-57.

4 National Federation of State High School Associations. Wrestling 2002

2003 rules book. Indianapolis: National Federation of State High School Associations, 2002.
5 Eliot AO, Baker CW. Eating disordered adolescent males. Adolescence $2001 ; 36: 535-43$

6 Sossin K, Gizis F, Marquart LF, et al. Nutrition beliefs, attitudes, and resource use of high school wrestling coaches. Int J Sport Nutr 1997;7:219-28.

7 Dick RW, Oppliger RA, Scott AC, et al. Wrestling with weight loss: the NCAA wrestling weight management policy. www.ncaasports.com. 